\title{
Head Circumference as a Body Weight Predictor in a Group of Sri
}

\section{Lankan Adults}

\author{
I. Ilayperuma ${ }^{1}$, B. C. I. J. Nanayakkara' ${ }^{2}$ L. P. L. B. Prabodha ${ }^{1}$, S. K. Y. I. \\ Kodikara $^{1}$, B. G. Nanayakkara ${ }^{1}$, N. K. Palahepitiya ${ }^{1}$
}

\begin{abstract}
Introduction: Accurate estimation of the body weight (BW) increases the safety and effectiveness of medical and pharmacological interventions. However, various situations make it difficult or even impossible to obtain a patient's body weight. In those instances, the need for an alternate method of weight determination arises. Consequently, several studies have proposed obtaining BW through prediction formulas based on various anthropometric variables.
\end{abstract}

Objective: Despite its' potential practical utility, little is known concerning the relationship between head circumference ( $\mathrm{HC}$ ) and BW among the adult Sri Lankans. The goal of this study was to propose population and gender specific regression formula for BW estimation using $\mathrm{HC}$.

Material \& method: Body weight and HC was recorded in a total of 156 cadavers: male: $n=74$; female: $n=82$. Subjects with any craniofacial deformities or neurological disorders were excluded from the study.

Results: The mean BW (kg) (male: $53.78 \pm 14.14$; female: $47.91 \pm 7.26)$ and HC (cm) (male: $54.09 \pm 3.28$; female: $52.88 \pm 2.83$ ) of the study subjects were found to be significantly different $(\mathrm{P}<0.01)$ between the genders. Correlation coefficient between the BW and HC was statistically significant and positive in both males (0.745) and females (0.365) indicating a strong relationship between the two parameters. Linear regression formulae for the prediction of BW using the $\mathrm{HC}$ were derived as follows: male: $31.27+1.57(\mathrm{HC})$; female: $53.09+1.91(\mathrm{HC})$.

Conclusion: Weight prediction equations that require a measuring tape as the only tool provides a practical alternative for the weight estimation of patients who are unable to walk due to various reasons. The use of anthropometric measurement such as $\mathrm{HC}$ is a simple, cost effective, non-invasive and objective method for BW prediction. Accurate prediction of a patient's weight will in turn, reduce potential drug

\footnotetext{
${ }^{1}$ Department of Anatomy, Faculty of Medicine, University of Ruhuna, Sri Lanka.

${ }^{2}$ Department of Surgery, Faculty of Medicine, Kotalawela Defense University, Sri Lanka.
} 
dosing errors that may occur when weight is estimated only by visual observation in emergency situations. Complementary studies are necessary to evaluate the applicability of these equations in other age groups too.

Key words: Body weight, head circumference, Sri Lankans

\section{INTRODUCTION}

Body weight is an important anthropometric measurement in assessing nutritional status and the risk of cardiovascular disease and type 2 diabetes, predicting caloric expenditure and calculating body mass index of an individual $(1,2)$. Body weight also forms the basis for calculating pharmacological doses of drugs or volume for resuscitation and pulmonary capacities in ventilated patients (1).

There are many instances where precise body weight of a patient is practically difficult or impossible to obtain using standardized methods. For example, in immobilized patients who are bedridden or in wheelchairs, in emergency setting when patients are unable to stand on a scale to be weighed accurately or clearly state their most recent weight due to altered mental status or some patients may simply do not know their own recent weight (3). Furthermore, scales integrated to hospital beds are not available in many health care institutions due to high cost. Consequently, various studies have proposed obtaining body weight through prediction formulas based on various anthropometric variables such as recumbent measures of arm and calf circumferences, triceps and subscapular skinfolds, knee height, abdominal circumference and cranial dimensions in different populations (3, 4,5). As the cranial dimensions are influenced by the race, sex and age of an individual, the need for race, age and sex specific formulae is also proved beyond doubt (6). It is important that predictive formulas are valid for a particular population in which they will be used so that the equations cover the characteristics of that population. Head circumference or the occipito-frontal circumference is the greatest of the cranial dimensions which passes around the forehead anteriorly and the external occipital 
protuberance posteriorly $(6,7)$. It is a routine part of the physical examination of a child and is of great importance in detecting abnormal patterns of growth (8).

Evidence shows a clear racial trend in the cranial dimensions and cephalic indices among different populations such as, Caucasians, Indians, Turkman and native Fars groups, Kosov and Albanians, Iranians, Japanese, Serbs, Greek, Bulgarians, Mapuche individuals in Chile, Nigerians, Caucasians and Sri Lankans $(9,10,11$, $12,13,14,15)$. Therefore, knowledge on the cranial morphometry is important in the study and comparison of the crania of populations from different racial, geographic and dietary backgrounds. Such information is also useful in studies of primate phylogeny. In clinical practice, population and age specific data on cranial dimensions gives an indication of the growth and development of an individual and also any abnormalities of cranial size and shape (8).

Despite its significance and potential practical utility, little is known concerning the relationship between head circumference and body weight among adult Sri Lankans. Therefore, the goal of this study was to propose population and gender specific regression formula for body weight estimation using the circumference of the head.

\section{MATERIAL AND METHOD}

This study was conducted on total of 156 cadavers donated to the Faculty of Medicine, University of Ruhuna, Sri Lanka. The subjects were apparently healthy and without any craniofacial deformities belonging to the same ethnic group. They were from different parts of the island belonging to different socio-economic status. The age of the subjects ranged from $55-89$ years.

The body weight was recorded to the nearest $0.1 \mathrm{~kg}$ using a hanging balancer (Avery). Head circumference data were recorded as the maximum circumference of the head measured from just above the glabella to the area near the top of the occipital bone (opisthocranion) (6) using a flexible measuring tape capable of measuring to the nearest $0.1 \mathrm{~cm}$. The above measurements were recorded at a fixed time between $14.00-16.30$ hours to 
eliminate discrepancies due to diurnal variation. All the measurements were repeated thrice and the mean was taken for further analysis. Furthermore, the measurements were recorded by the same person to minimize the errors in methodology.

Results were expressed as mean \pm SD and analyzed using the Statistical Package for Social Sciences (SPSS), $15^{\text {th }}$ version. A comparison of the mean values between the genders was performed using the t-test. $\mathrm{P}$ value < 0.01 was considered statistically significant. The strength of association between the head circumference and body weight was measured by the Pearsons correlation coefficient. Equations for weight estimation were obtained by linear regression analysis.

\section{RESULTS}

The mean ages of the study subjects (male: $75.49 \pm 7.69$; female: $74.66 \pm$ 5.091) were not significantly different between the genders (Table I). Gender differences with respect to the head circumference and body weight was found to be significantly larger in males compared to females $(\mathrm{P}<0.01)$ (Table I, Figures 1a \& 1b).

A linear regression analysis was performed for estimation of body weight using the head circumference as an independent variable. Pearsons correlation coefficient was used to examine the relationship between head circumference and body weight according to the gender. Correlation coefficient between the body weight and head circumference was found to be statistically significant and positive in both males (0.745) and females (0.365).

Scatter plots and linear regression lines demonstrating the relationship between body weight and head circumference are illustrated in Figures $2 \mathrm{a}, \mathrm{b} \& \mathrm{c}$. Linear regression formulae for the prediction of body weight using head circumference were derived as follows: male: $31.27+1.57$ (HC); female: $53.09+1.91(\mathrm{HC})$; both male and female (combined): $46.73+1.83(\mathrm{HC})$ 
Ilayperuma, I., Nanayakkara, B. C. I. J., Prabodha, L. P. L. B., Kodikara, S.K.Y.I., Nanayakkara, B. G., Palahepitiya, N. K., Head Circumference as a Body Weight Predictor in a Group of Sri Lankan Adults. Sri Lanka Anatomy Journal (SLAJ), 1(1):6 - 15, 2017.

Table I. Characteristics of the study subjects

\begin{tabular}{llll}
\hline Parameter & Female & Male & Both \\
\hline Total Number & 74 & 82 & 156 \\
Age range (years) & $68-83$ & $55-89$ & $55-89$ \\
Mean age (years) & $74.66 \pm 5.09$ & $75.49 \pm 7.69$ & $75.10 \pm 47.13$ \\
Body weight range $(\mathrm{Kg})$ & $30-57$ & $34-93$ & $30-93$ \\
Mean body weight $(\mathrm{Kg})$ & $47.91 \pm 7.26 *$ & $53.78 \pm 14.14$ & $50.99 \pm 11.75$ \\
HC range $(\mathrm{cm})$ & $58.5-50$ & $60-43.2$ & $60-43.2$ \\
Mean HC $(\mathrm{cm})$ & $52.88 \pm 2.83 *$ & $54.09 \pm 3.28$ & $53.51 \pm 3.13$ \\
& & & \\
\hline
\end{tabular}

$* \mathrm{P}<0.01$

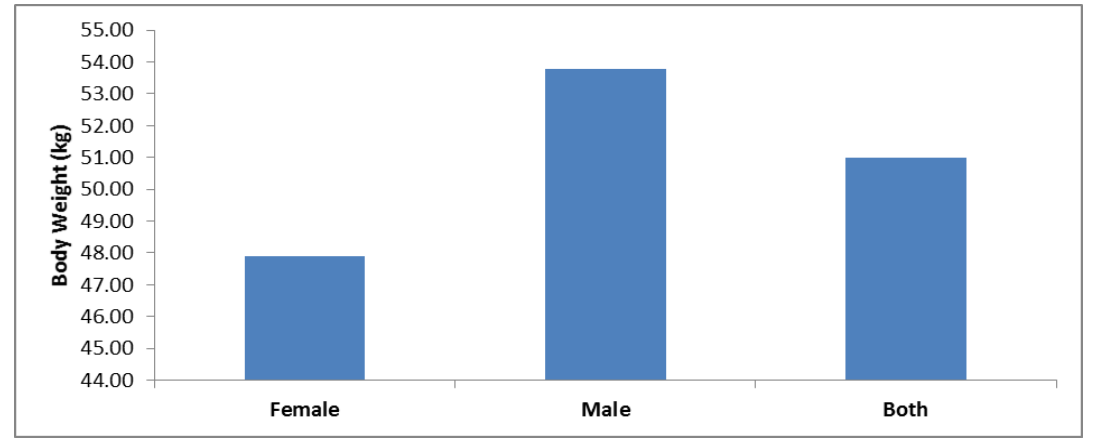

Figure 1a. Gender differences in body weight

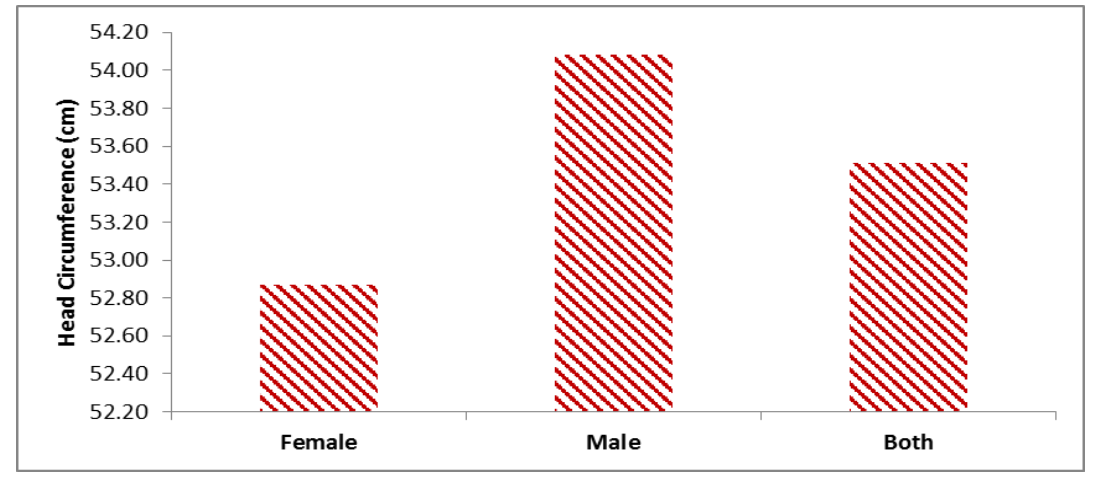

Figure 1b. Gender differences in head circumference 
Ilayperuma, I., Nanayakkara, B. C. I. J., Prabodha, L. P. L. B., Kodikara, S.K.Y.I., Nanayakkara, B. G., Palahepitiya, N. K., Head Circumference as a Body Weight Predictor in a Group of Sri Lankan Adults. Sri Lanka Anatomy Journal (SLAJ), 1(1):6 - 15, 2017

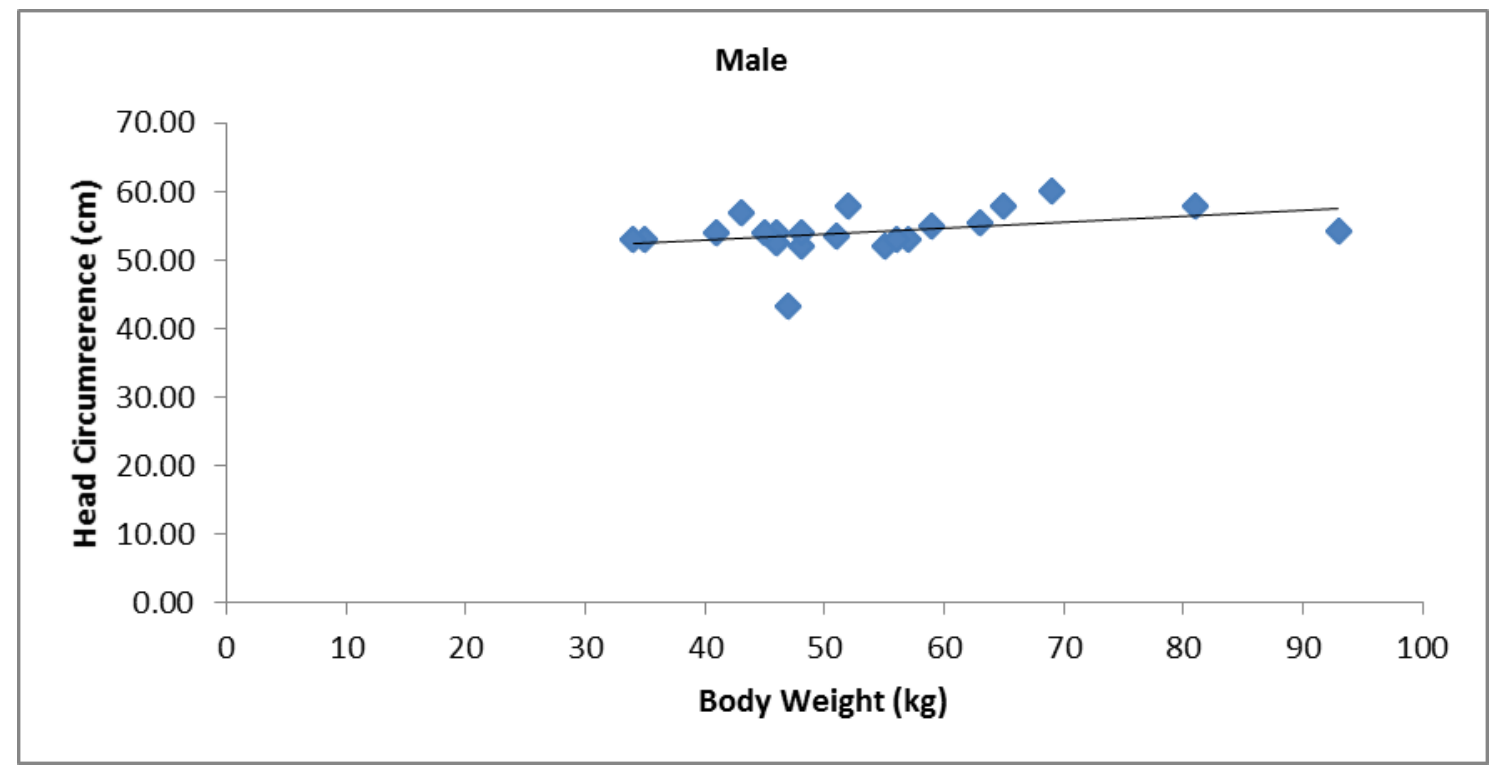

Figure 2a. Scatter plot and regression line demonstrating the relationship between body weight $(\mathrm{kg})$ and head circumference $(\mathrm{cm})$ in males

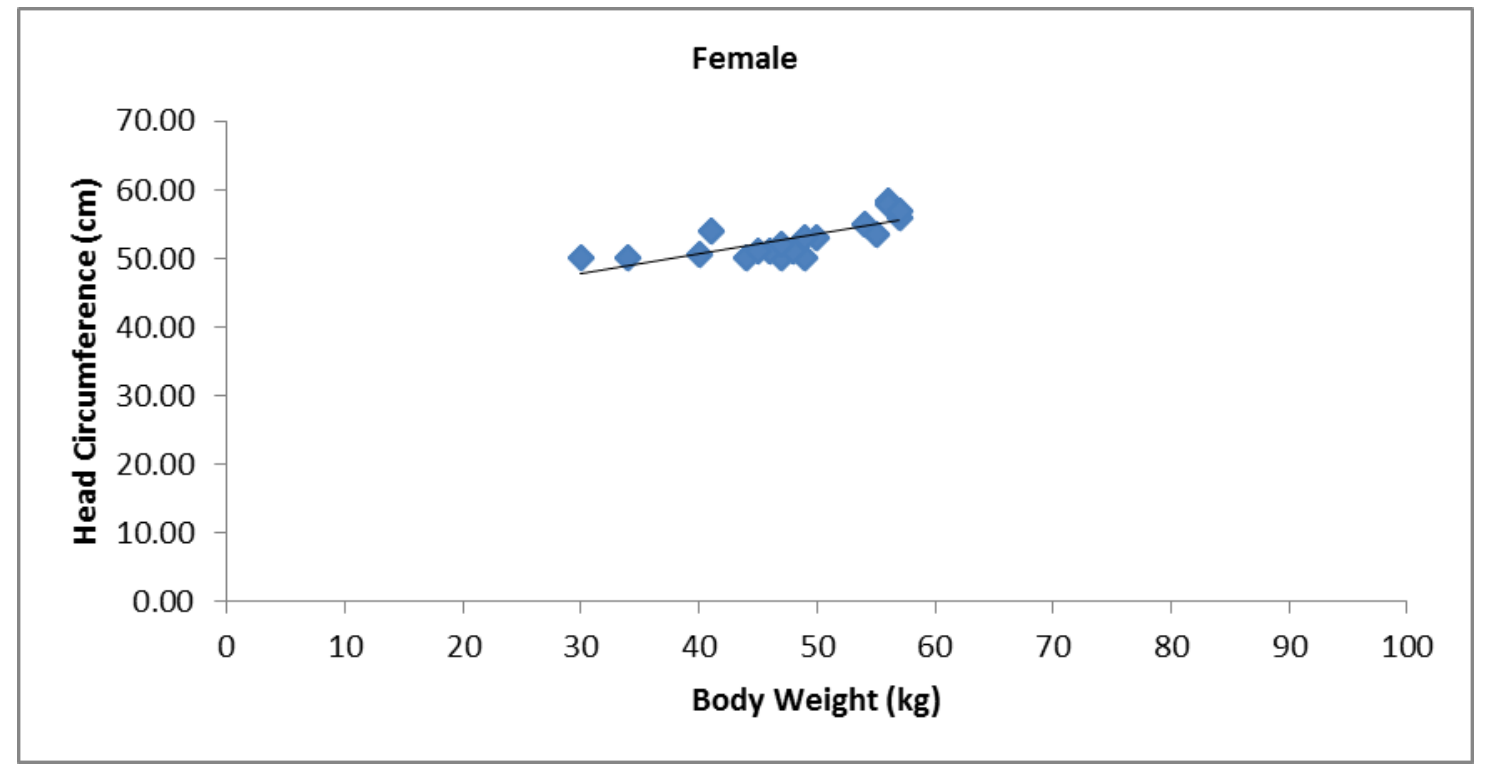

Figure 2b. Scatter plot and regression line demonstrating the relationship between body weight $(\mathrm{kg})$ and head circumference $(\mathrm{cm})$ in females 


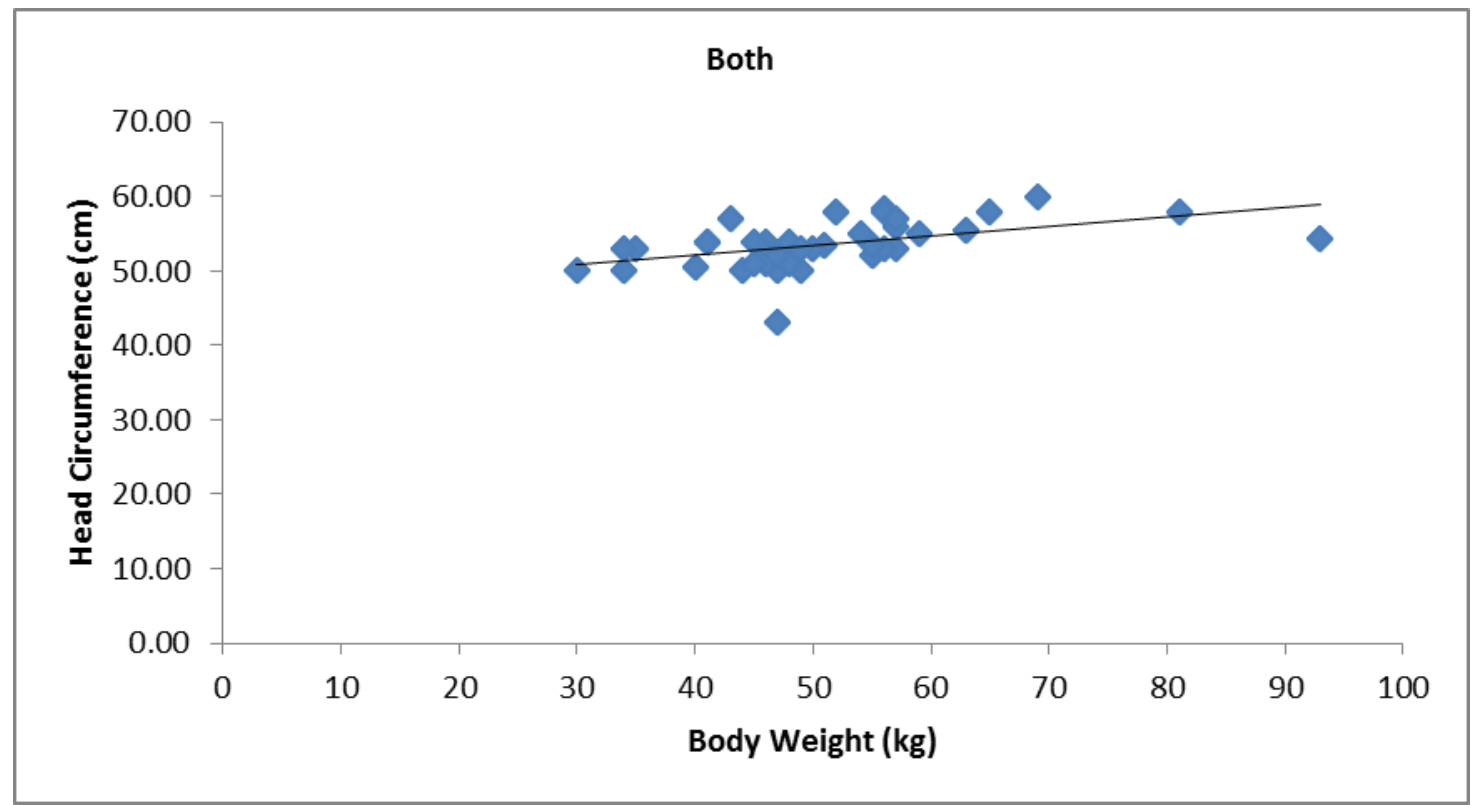

Figure 2c. Scatter plot and regression line demonstrating the relationship between body weight $(\mathrm{kg})$ and head circumference $(\mathrm{cm})$ in both males and females

\section{DISCUSSION}

The present study provides valuable data pertaining to the head circumference and its correlation with the body weight in an adult Sri Lankan population.

Several rare conditions have been identified where macrocephaly persists into adulthood: Cowden disease, tuberous sclerosis, neurofibromatosis type 1, Weaver syndrome, Sotos syndrome, autism spectrum disorder $(16,17,18)$. It was also important to note that adult patients with autism spectrum disorder displayed a statistically significant increase in head circumference relative to norms (18). Therefore, measurements of head circumference play a vital role in the diagnosis of such conditions in adulthood (19). In addition, some of these syndromes, like tuberous sclerosis and neurofibromatosis type 1 have an adulthood age of onset which further emphasizes the need for adult head circumference normative data (18). Furthermore, it is stated that approximately $50 \%$ of normal head size variation is familial. Therefore adjustment of a child's head size value by the average parental value permits more refined assessment of head size when there is a suspected abnormality (19). 
Variety of non-metric and metric parameters has been utilized in the assessment of ethnic and gender differences in cranio-facial morphology. The non-metric parameters are subjective as no quantitative techniques are devised. On the other hand, features that can be expressed as actual measurements, like head circumference, provide more objective racial and gender diversity assessment of the crania (5).

Diverse craniometric approaches have been utilized to estimate the cranial dimensions either on dry skulls, cadavers or living subjects. Over the course of this study head circumference was recorded using a flexible measuring tape. Cephalometry is reliable, relatively easy and quick to apply. This approach has the added advantage as it does not require any sophisticated techniques. Taken together, cephalometry continues to be the most versatile technique in the investigations of the craniofacial dimensions (21).

The gender divergence in head circumference observed in our study supports the previous observations (15). This further emphasizes the significance of applying the anatomical variation data to an individual subject in a given population. The need for the alternative formulae for the genders is also proved as the rate of skeletal maturity in males and females vary during the course of growth and development (6). Body weight of the subjects was significantly different between the genders. Correlation coefficients between the body weight and head circumference among adult Sri Lankans were found to be statistically significant and positive indicating a strong relationship between the two parameters. The correlation between $\mathrm{HC}$ and body weight could be a reflection of the bone mass and brain size as a heavier brain is likely to add to the individuals total body weight (18).

Variety of factors such as age, race, gender and nutritional status affect human development and growth. Therefore, different nomograms are required for different populations (6). The present study for the first time documents such norms for head circumference and presents gender specific linear regression models for weight prediction in an adult Sri Lankan population. These formulae are valid for the age group (55 - 89_years) of the subjects. It is widely accepted that cranial morphology varies with the age of an individual (22).

Accurate estimation of the body weight increases the safety and effectiveness of medical and pharmacological interventions. However, various situations make it difficult or even impossible to 
obtain a patient's body weight and in those instances, the need for an alternate method of weight determination arises. The population, gender and age specific regression models proposed will be of practical use as facilities for weighing a patient in bed are not available in many health care institutions in the developing countries. Furthermore its applicability

\section{REFERENCES}

1. Herout PM, Erstad BL. Medication errors involving continuously infused medications in a surgical intensive care unit. Crit Care Med 2004; 32: 428-32.

2. Bays HE, Chapman RH, Grandy S. The relationship of body mass index to diabetes mellitus, hypertension and dyslipidaemia: comparison of data from two national surveys. Int J Clin Prac 2007; 61: 737-747.

3. Rabito EI, Vannucchi GB, Suen VMM, Castilho N, Laércio L. Weight and height prediction of immobilized patients. Rev Nutr 2006; 19: 655-661.

4. Buckley RG, Stehman CR, Dos Santos FL, Riffenburgh RH, Swenson A, Mjos N, Brewer M, Mulligan S. Bedside method to estimate actual body weight in the Emergency Department. J Emerg Med 2012; 42: $100-104$.

5. Chumlea WC, Guo S, Roche AF, Steinbaugh ML. Prediction of body weight for the non-ambulatory elderly from anthropometry. J Am Diet Assoc 1988; 88: $564-568$.

6. Krishan K. Estimation of stature from cephalo-facial anthropometry in north Indian Population. Foren Sci Int 2008; 181:521-6, 2008.

7. Williams PL, Bannister LH, Berry MM, Collins P, Dyson M, Dussek JE. Gray's Anatomy: The anatomical basis of medicine and surgery. $38^{\text {th }}$ edition. New York, Churchill Livingstone, 2000. requires only a flexible measuring tape and the gender of the patient to estimate the body weight.

Alternate method to accurately predict a patient's weight, may in turn, reduce drug dosing errors that may occur when weight is estimated only by visual observation in emergency situations

(4).

8. Harper C, Krill J, Raven D \& Jones N. Intracranial cavity volumes: a new method and its potential applications. Neuropathol Appl Neurobiol 1984; 10: 25-32.

9. Abolhasanzadeh A \& Farahani MR. Standarded international classification of head shapes of 22-24 years old in Tehran. J Res Med 2003; 26: 281-5.

10. Rexhepi A \& Meka V. Cephalofacial morphological characteristics of Albanian Kosova population. Int $\mathbf{J}$ Morphol 2008; 26: 935-40.

11. Kasai K, Richards TC \& Brown T. Comparative study of craniofacial morphology in Japanese and Australian aboriginal populations. Hum Biol 1993; 65: 821-34.

12. Obikili EN \& Singh SP. Secular growth trend in the adult stature of Nigerians. Orient J Med 1992; 4: 4447.

13. Del Sol M. Cephalic index in a group of Mapuche individuals in the IX region of Chile. Int J Morphol 2005; 23: 241-246.

14. Okupe RF, Coker OO \& Gbajumo SA. Assessment of biparietal diameter during normal pregnancy in Nigerian women. Br J Obstet Gynaecol 1984; 99: 629-632.

15. Ilayperuma I. Evaluation of cephalic indices: a clue for racial and gender 
diversity. Int J Morphol 2011; 29: 112-117.

16. Winter RM \& Baraitser M. London dysmorphology database. Oxford, Oxford University Press, 1996.

17. Williams CA, Dagli A, Battaglia A. Genetic disorders associated with macrocephaly. Am J Med Genet 2008; 146: 2023-2037.

18. 18.Nguyen AKD, Simard-Meilleur AA, Berthiaume C, Godbout R, \& Mottron L. Head Circumference

in Canadian Male Adults: Development of a normalized chart. Int J Morphol 2012; 30: 1474-1480.

19. McCaffery P \& Deutsch CK, Macrocephaly and the control of brain growth in autistic disorders. Prog Neurobiol 2005; 77: 38-56.

20. Weaver DD, Christian JC. Familial variation of head size and adjustment for parental head circumference. J Pediatr 1980; 96: 990-994.

21. Grant TM, Peter AM. Size and shape measurement in contemporary cephalimeyrics. Eur J Orthod 2003; 25: 231-242.

22. Wolf H, Kruggel F, Hensel A, Wahlund LO, Arendt T \& Gertz HJ. The relationship between head size and intracranial volume in elderly subjects. Brain Res 2003; 23: 74-80.

\section{CORRESPONDENCE:}

Professor I. Ilayperuma

Department of Anatomy, Faculty of Medicine, University of Ruhuna, Sri Lanka.

Email- iisurani@yahoo.com

Received: June 2017

Accepted: August 2017 